\title{
Brachypodium: A Potential Model Host for Fungal Pathogens of Turfgrasses
}

\author{
Renee A. Rioux, Benjamin J. Van Ryzin, and James P. Kerns
}

First author: Department of Plant Pathology, University of Wisconsin-Madison, Madison 53706; and second and third authors: Department of Entomology and Plant Pathology, North Carolina State University, Raleigh 27695. Accepted for publication 22 January 2017.

\begin{abstract}
Brachypodium distachyon is a $\mathrm{C} 3$ grass that is an attractive model host system for studying pathogenicity of major turfgrass pathogens due to its genetic similarity to many cool-season turfgrasses. Infection assays with two or more isolates of the casual agents of dollar spot, brown patch, and Microdochium patch resulted in compatible interactions with $B$. distachyon inbred line $\mathrm{Bd} 21-3$. The symptoms produced by these pathogens on $\mathrm{Bd} 21-3$ closely resembled those observed on the natural turfgrass host (creeping bentgrass), demonstrating that $B$. distachyon is susceptible to the fungal pathogens that cause dollar spot, brown patch, and Microdochium patch on
\end{abstract}

ABSTRACT

Turfgrass is the largest irrigated crop in the United States at roughly 35 million acres of land (Breuninger et al. 2013; Leinauer and Devitt 2013). Additionally, turf provides many functional, recreational, and ornamental benefits to human activities, making it an important provider of ecosystem services (Beard 1973). Professional turfgrass sectors include golf courses, sod production, institutional facilities, and management services such as lawn care and irrigation. Regardless of the turf sectors, high-quality turf is essential and is generally achieved through repeated applications of pesticides for weed, insect, and disease control. It is estimated that fungicide applications for disease management cost the golf industry alone \$174.40 million per year in the United States (Kerns and Tredway 2013). A single golf course may spend $\$ 20,000$ to 50,000 a year on fungicide applications for putting greens, a small but intensively managed part of the golf course. In addition to the economic costs associated with repeated fungicide applications, nontarget effects of fungicides can be hazardous to the environment (Baird et al. 1999; Baris et al. 2010) and the development of fungicide resistance in target pathogens is a common result of repeated exposure to a single active ingredient (Latin 2011). Biological and cultural controls offer alternatives to frequent fungicide applications but fail to consistently achieve adequate disease suppression comparable with that of chemical management tactics (Koppenhöfer et al. 2013).

Breeding popular turfgrass species for better disease resistance is the primary goal for sustainable disease management in golf course settings (Bonos et al. 2006). Due to the lack of genomic sequence data and other genetic tools for major turfgrass species, breeding for disease resistance has largely been based on traditional methods and has proceeded at a slow, albeit steady, pace (Belanger et al. 2004; Bonos et al. 2004, 2006; Studer et al. 2007). A biologically relevant model host for important turfgrass pathogens would enable precise identification of key genes involved in disease resistance or susceptibility. These genes could then be specifically targeted in turfgrass breeding efforts to produce a more streamlined approach toward development of disease-resistant cultivars (Spangenberg

Corresponding author: R. A. Rioux; E-mail address: rrioux@wisc.edu

(C) 2017 The American Phytopathological Society turfgrasses. The interaction between Sclerotinia homoeocarpa isolates and Brachypodium ecotypes was also investigated. Interestingly, differential responses of these ecotypes to $S$. homoeocarpa isolates was found, particularly when comparing $B$. distachyon to $B$. hybridum ecotypes. Taken together, these findings demonstrate that $B$. distachyon can be used as a model host system for these turfgrass diseases and leveraged for studies of molecular mechanisms contributing to host resistance.

Additional keywords: host-pathogen interactions, snow mold.

et al. 2005). Unfortunately, an ideal model host for turfgrass pathogenesis studies has not previously been identified.

The genus Brachypodium includes C3 grass species in the subfamily Pooideae and is closely related to the major cool-season grass tribes Avenae, Bromae, Poeae, and Triticeae (Kellogg 2001). Just over a decade ago, a member of this genus, Brachypodium distachyon (L.) P. Beauv., was proposed as a novel model system for both turf-type or forage grasses and temperate cereals (Draper et al. 2001). More recently, the biofuels industry has adopted B. distachyon as a model due to its similarities with key bioenergy crops, including Miscanthus spp. and switchgrass (Gomez et al 2008; Zhao et al. 2011). Much like the dicot model plant Arabidopsis thaliana, B. distachyon is small, fast growing, and amenable to inbreeding and has a simple diploid genome (Draper et al. 2001). Genetic resources for $B$. distachyon have steadily increased since its emergence as a model species, including the release of a high-quality, annotated complete genomic sequence in 2010 (The International Brachypodium Initiative 2010). The availability of a genomic sequence and accompanying genetic resources (Bragg et al. 2012; Garvin et al. 2008) (http://brachybase.org; http://www.phytozome. net; www.brachypodium.org) have encouraged widespread use of $B$. distachyon as a model for surveys of evolutionary genetics in grasses and comparisons of grass genomes (Bossolini et al. 2007; The International Brachypodium Initiative 2010). B. distachyon has also been successfully used in multiple cases to generate and refine linkage maps for cool-season grasses (Chutimanitsakun et al. 2011; Zhang et al. 2010; Zhao et al. 2011) and is considered the optimal model plant for members of the Poaceae family (Lyons and Scholthof 2015).

Host-pathogen interactions between $B$. distachyon and plant pathogens have previously been described for a number of economically important monocot diseases (Ayliffe et al. 2013; Barbieri et al. 2011; Figueroa et al. 2013; Parker et al. 2008; Peraldi et al. 2011, 2014; Routledge et al 2004; Sandoya and de Oliviera Buanafina 2014, Schneebeli et al. 2016; Zhong et al. 2015) and a review on the status of Brachypodium as an emerging model for cereal pathosystems was recently provided by Fitzgerald and colleagues (2015). The earliest of these studies focused on the interaction between B. distachyon and the model pathogen Magnaporthe grisea, causal agent of blast disease on rice and other grasses (Routledge et al. 2004). Not only did this research demonstrate the utility of B. distachyon as a model for host-pathogen interactions but it also 
demonstrated that the $B$. distachyon-M. grisea interaction mirrored interactions of this pathogen with rice at both the histological and molecular levels, including the presence of resistance conferred by a single dominant gene (Routledge et al. 2004).

$B$. distachyon has also been proposed as an optimal model host for studying Fusarium diseases of wheat because infection of $B$. distachyon is remarkably similar to the infection process observed in wheat, including infection of $B$. distachyon spikes by the Fusarium head blight pathogens Fusarium graminearum and $F$. culmorum (Peraldi et al. 2011). Compatible interactions have also been described between B. distachyon and Oculimacula spp. and B. distachyon and Ramularia collo-cygni, the causal agents of eyespot and Ramularia leaf spot of cereal, respectively (Peraldi et al. 2014). Multiple researchers have characterized the interactions between Brachypodium spp. and various cereal rust pathogens, including Puccinia graminis, $P$. brachypodii, P. triticina, and P. striiformis (Ayliffe et al. 2013; Barbieri et al. 2011; Figueroa et al. 2013). Collectively, these studies have demonstrated a range of responses to rust pathogens in different Brachypodium ecotypes and the utility of Brachypodium spp. as a model system for studying molecular components of incompatibility and nonhost resistance to rust pathogens.

The present research aims to extend the body of work on Brachypodium spp.-cereal pathogen interactions by evaluating the compatibility of $B$. distachyon with three major fungal pathogens of turfgrass: Sclerotinia homoeocarpa, Microdochium nivale, and Rhizoctonia solani. In addition, this research explores the genetic diversity present in wild ecotypes in response to $S$. homoeocarpa isolates and paves the way for widespread use of Brachypodium spp. as a model for turfgrass pathogens.

\section{MATERIALS AND METHODS}

Biological materials. All pathogen isolates (Table 1) were obtained from symptomatic turfgrass using standard methods or were obtained from colleagues. Briefly, turfgrass blades displaying symptoms characteristic for dollar spot, Microdochium patch, or brown patch were surface disinfested in changed 10\% Clorox solution and rinsed with distilled water. Individual blades were then excised and placed on antibiotic- or $\mathrm{pH}$-amended media and incubated for at least $48 \mathrm{~h}$. Hyphal tips of colonies growing from symptomatic leaf areas and resembling the pathogens of interest in growth rate, growth pattern, and mycelial pigmentation were excised and transferred to fresh media to obtain pure cultures. Cultures were identified as the pathogens of interest based on colony morphology, conidial production and morphology, and sequencing of the internal transcribed spacer (ITS) region using conserved fungal (ITS 4 and 5) primers (White et al. 1990). Cultures were maintained in the dark at $21 \pm 2^{\circ} \mathrm{C}$ on potato dextrose agar (PDA) plates and transferred weekly to fresh media. Additionally, long-term stocks of all isolates were stored at $-80^{\circ} \mathrm{C}$ on filter paper disks.

Seed for B. distachyon inbred line $\mathrm{Bd} 21-3$ was obtained from researchers at Cornell University. B. distachyon accessions (Table 2) were ordered from the United States Department of Agriculture National Plant Germplasm System (http://www.ars-grin.gov/npgs) and have previously been assessed for leaf and stripe rust susceptibility (Barbieri et al. 2011). B. distachyon was cultivated in 8 -cm-diameter pots filled with a 50:50 ( vol/vol) mixture of calcine clay (Turface, Buffalo Grove, IL) and potting mix. Pots were placed into plastic flats to allow for bottom watering and a single seed was placed in each pot. To promote germination, a propagation dome was placed over pots for the first 3 to 5 days after sowing. This was then removed to allow for plant growth. Adequate plant nutrition was maintained by bottom-watering once weekly with quarter-strength Miracle-Gro Water Soluble All-Purpose Plant Food (The Scotts Company, LLC, Marysville, OH) . For the first 3 weeks of growth, all plants were maintained in a growth room with a 14-h photoperiod at $24 \pm 2{ }^{\circ} \mathrm{C}$, with a fluorescent light intensity of 225 to $275 \mu \mathrm{mol} \mathrm{m}{ }^{-2} \mathrm{~s}^{-1}$. Plants to be inoculated with $R$. solani, $S$. homeoecarpa, and $M$. nivale were moved to the appropriate controlled-environment chambers 4 weeks after seeding to allow time for acclimation to inoculation conditions prior to pathogen challenge.

TABLE 1. Fungal isolates used for Brachypodium distachyon inoculations

\begin{tabular}{|c|c|c|c|c|}
\hline Species & Isolate code & Collection site & Host species & Disease \\
\hline Rhizoctonia solani (AG2-2 IIIB) & Rs & North Carolina & Creeping bentgrass & Brown patch \\
\hline R. solani (AG2-2 IIIB) & SRSE & North Carolina & Creeping bentgrass & Brown patch \\
\hline Microdochium nivale & $\mathrm{BH} 7$ & Wisconsin & Creeping bentgrass & Snow mold \\
\hline M. nivale & MN5 & Illinois & Creeping bentgrass & Snow mold \\
\hline Sclerotinia homoeocarpa & $2 \mathrm{~F} 92-1^{\mathrm{y}}$ & Wisconsin & Creeping bentgrass & Dollar spot \\
\hline S. homoeocarpa & Heath1A & Wisconsin & Creeping bentgrass & Dollar spot \\
\hline S. homoeocarpa & LFD8 & North Carolina & Bermudagrass & Dollar spot \\
\hline S. homoeocarpa & OJN9z & Wisconsin & Creeping bentgrass & Dollar spot \\
\hline S. homoeocarpa & $\mathrm{S} 10^{\mathrm{z}}$ & Wisconsin & Creeping bentgrass & Dollar spot \\
\hline
\end{tabular}

y Previously described by Koch et al. (2009).

z Previously described by Rioux et al. (2014).

TABLE 2. Brachypodium accessions used for fungal inoculations and accession-isolate interaction evaluations

\begin{tabular}{|c|c|c|c|c|}
\hline Species $^{z}$ & Accession ID & Ploidy level & Origin & Inbred lines \\
\hline Brachypodium distachyon & $\mathrm{Bd} 21-3$ & Diploid & Iraq & $\ldots$ \\
\hline B. distachyon & PI 245730 & Diploid & Turkey & Bd18-1 \\
\hline B. distachyon & PI 254867 & Diploid & Iraq & $\mathrm{Bd} 21, \mathrm{Bd} 21-3$ \\
\hline B. hybridum & PI 226629 & Allotetraploid & Iran & Bd11-1, Bd11-2 \\
\hline B. hybridum & PI 227011 & Allotetraploid & Iran & Bd12-1, Bd12-2 \\
\hline B. hybridum & PI 233228 & Allotetraploid & Israel & $\mathrm{Bd} 13-1, \mathrm{Bd} 13-2$ \\
\hline B. hybridum & PI 239713 & Allotetraploid & Iran & Bd14-1, Bd14-2 \\
\hline B. hybridum & PI 287783 & Allotetraploid & Spain & $\mathrm{Bd} 23-1, \mathrm{Bd} 23-2$ \\
\hline B. hybridum & PI 372187 & Allotetraploid & Uruguay & $\mathrm{Bd} 26-1, \mathrm{Bd} 26-2$ \\
\hline B. hybridum & PI 533105 & Allotetraploid & Australia & $\mathrm{Bd} 28$ \\
\hline
\end{tabular}

z Species designations are based on the reclassification of Brachypodium spp. based on ploidy level and other characteristics by Catalan and colleagues (2012). 
Bd21-3 growth chamber infection assays. Infection assays of Bd21-3 with all three fungal pathogens were set up as a randomized complete block design (RCBD) with three replicates, and each study was repeated three times. The majority of inoculations were performed using the Parafilm sachet method (Jia et al. 2012). Briefly, a 6-mm-diameter agar plug was excised from the advancing edge of fungal colonies with a sterile cork borer and adhered to the plant, mycelium-side against the plant, with a thin strip of Parafilm. Plugs were applied 2 to $4 \mathrm{~cm}$ from the base of the plant. Control plants were mock inoculated with PDA plugs lacking mycelium. Due to differing growth rates of the fungal pathogens used in these studies, the age of cultures when used for inoculation varied, as described below.

$S$. homoeocarpa inoculations were performed in a controlledenvironment room held at $24 \pm 2^{\circ} \mathrm{C}$ with a 14-h photoperiod. Fiveday-old cultures were used for inoculation. The Parafilm sachet method alone was adequate for inducing consistent symptom development. Disease severity, assessed as the percentage of tissue affected, was rated every $24 \mathrm{~h}$ using the Horsfall-Barratt scale (Horsfall and Barratt 1945). To determine pathogenicity of $S$. homoeocarpa on B. distachyon, an initial assay was conducted with $\mathrm{Bd} 21-3$ and four Wisconsin isolates originally collected from creeping bentgrass (2F92-1, Heath1A, OJN9, and S10). Following successful demonstration of infection on Bd21-3, two of these isolates (2F92-1 and OJN9) and LFD8, a North Carolina isolate from bermudagrass, were used for screening against Brachypodium ecotypes. LFD8 was included to increase the geographic and host diversity of isolates used in this study.

A controlled-environment chamber at $28 \pm 4^{\circ} \mathrm{C}$ with a 10 -h photoperiod was used for $R$. solani inoculations. $R$. solani cultures were 5 days old at the time of inoculation. To achieve consistent disease pressure and symptom development, relative humidity was maintained at or near $100 \%$ by covering flats with humidity domes. Disease severity was rated at 5 days postinoculation, as described for $S$. homoeocarpa above. The experiment was conducted as an RCBD with four replicates for each treatment within each of three experimental repetitions, for a total of 12 data points per isolate.

Due to the slower growth of $M$. nivale, inoculations were performed using 7-day-old cultures. Inoculated plants were placed in a growth chamber held at a constant temperature of $21^{\circ} \mathrm{C}$ with a 14-h photoperiod. The lower temperature mimicked the cool conditions under which $M$. nivale typically infects. A humidity dome was placed over inoculated plants to maintain high relative humidity and disease severity ratings were performed at 5 days postinoculation, as described above. Similar to $R$. solani, there were four treatment replicates within each of three experimental repetitions.

Following the 5-day disease incubation period and rating of symptom severity, all plants were photographed to document and compare symptoms. Pathogens were reisolated from symptomatic material to confirm presence of the inoculated pathogen. This was done by briefly surface disinfesting diseased $B$. distachyon foliage in $10 \%$ Clorox solution, rinsing with sterile deionized water, and plating small pieces of the diseased plant material on antibioticamended medium. Plates were incubated at room temperature for up to 1 week to allow time for the target fungi to grow, and identity was confirmed by colony morphology.

Brachypodium natural ecotype by $S$. homoeocarpa isolate infection assays. Twelve natural ecotypes, as well as the inbred line Bd21-3, and three $S$. homoeocarpa isolates were used for ecotype-isolate interaction infection assays. Brachypodium ecotypes differed in ploidy level and included representatives from

TABLE 3. Specific comparisons of symptom severity for Brachypodium ecotype-Sclerotinia homoeocarpa isolate interactions ${ }^{\mathrm{w}}$

\begin{tabular}{|c|c|c|c|c|c|c|}
\hline Isolates $^{\mathrm{x}}$ & Group $1^{y}$ & Group $2^{z}$ & Group 1 mean (SE) & Group 2 mean (SE) & $F$ value & $P$ value \\
\hline \multirow[t]{8}{*}{ All } & B. distachyon eco & B. hybridum & $39.54(2.88)$ & $50.76(1.80)$ & 15.91 & $<0.0001^{* * *}$ \\
\hline & All B. distachyon & B. hybridum & $42.55(2.64)$ & $50.76(1.80)$ & 12.61 & $0.0004^{* * * *}$ \\
\hline & $\mathrm{Bd} 21-3$ & PI 254867 & $48.33(5.16)$ & $43.70(2.57)$ & 0.69 & 0.4085 \\
\hline & $\mathrm{Bd} 21-3$ & PI 245370 & $48.33(5.16)$ & $35.37(4.04)$ & 5.37 & $0.0215^{*}$ \\
\hline & $\mathrm{Bd} 21-3$ & PI 639818 & $48.33(5.16)$ & $42.78(4.75)$ & 0.99 & 0.3214 \\
\hline & PI254867 & PI 245730 & $43.70(2.57)$ & $35.37(4.04)$ & 2.36 & 0.1257 \\
\hline & PI 254867 & PI 639818 & $43.70(2.57)$ & $42.78(4.75)$ & 0.03 & 0.8646 \\
\hline & PI 639818 & PI 245730 & $42.78(4.75)$ & $35.37(4.04)$ & 1.86 & 0.1733 \\
\hline \multirow[t]{8}{*}{ 2F92-1 } & B. distachyon eco & B. hybridum & $37.04(4.27)$ & $50.36(3.11)$ & 8.10 & $0.0054 * *$ \\
\hline & All B. distachyon & B. hybridum & $37.93(3.15)$ & $50.36(3.11)$ & 8.45 & $0.0045^{* *}$ \\
\hline & $\mathrm{Bd} 21-3$ & PI 254867 & $40.63(9.23)$ & $43.33(6.45)$ & 0.07 & 0.7897 \\
\hline & $\mathrm{Bd} 21-3$ & PI 245370 & $40.63(9.23)$ & $28.89(7.4)$ & 1.34 & 0.2492 \\
\hline & $\mathrm{Bd} 21-3$ & PI 639818 & $40.63(9.23)$ & $38.89(5.58)$ & 0.03 & 0.8642 \\
\hline & PI254867 & PI 245730 & $43.33(6.45)$ & $28.89(7.4)$ & 2.16 & 0.1447 \\
\hline & PI 254867 & PI 639818 & $43.33(6.45)$ & $38.89(5.58)$ & 0.20 & 0.6519 \\
\hline & PI 639818 & PI 245730 & $38.89(5.58)$ & $28.89(7.4)$ & 1.86 & 0.1733 \\
\hline \multirow[t]{8}{*}{ OJN9 } & B. distachyon eco & B. hybridum & $44.81(3.83)$ & $57.24(2.73)$ & 7.44 & $0.076^{* * *}$ \\
\hline & All B. distachyon & B. hybridum & $48.14(4.29)$ & $57.24(2.73)$ & 4.88 & $0.0296 *$ \\
\hline & $\mathrm{Bd} 21-3$ & PI 254867 & $58.13(5.08)$ & $39.44(5.86)$ & 3.40 & 0.0682 \\
\hline & $\mathrm{Bd} 21-3$ & PI 245370 & $58.13(5.08)$ & $42.78(6.88)$ & 2.30 & 0.1330 \\
\hline & $\mathrm{Bd} 21-3$ & PI 639818 & $58.13(5.08)$ & $52.22(8.04)$ & 0.34 & 0.5614 \\
\hline & PI254867 & PI 245730 & $39.44(5.86)$ & $42.78(6.88)$ & 1.12 & 0.1352 \\
\hline & PI 254867 & PI 639818 & $39.44(5.86)$ & $52.22(8.04)$ & 1.69 & 0.1966 \\
\hline & PI 639818 & PI 245730 & $52.22(8.04)$ & $42.78(6.88)$ & 0.92 & 0.3389 \\
\hline \multirow[t]{8}{*}{ LFD8 } & B. distachyon eco & B. hybridum & $40.00(4.24)$ & $44.70(2.17)$ & 1.44 & 0.2323 \\
\hline & All B. distachyon & B. hybridum & $41.56(3.38)$ & $44.70(2.17)$ & 0.78 & 0.3800 \\
\hline & $\mathrm{Bd} 21-3$ & PI 254867 & $46.25(7.06)$ & $48.33(5.65)$ & 0.06 & 0.8073 \\
\hline & $\mathrm{Bd} 21-3$ & PI 245370 & $46.25(7.06)$ & $34.44(5.56)$ & 1.92 & 0.1691 \\
\hline & $\mathrm{Bd} 21-3$ & PI 639818 & $46.25(7.06)$ & $37.22(5.72)$ & 1.12 & 0.2920 \\
\hline & PI254867 & PI 245730 & $48.33(5.65)$ & $34.44(5.56)$ & 2.82 & 0.0961 \\
\hline & PI 254867 & PI 639818 & $48.33(5.65)$ & $37.22(5.72)$ & 1.81 & 0.1820 \\
\hline & PI 639818 & PI 245730 & $37.22(5.72)$ & $34.44(5.56)$ & 0.11 & 0.7357 \\
\hline
\end{tabular}

w $\mathrm{SE}=$ standard error.

x $S$. homoeocarpa isolates.

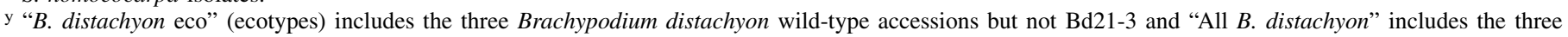
$B$. distachyon wild-type accessions and $\mathrm{Bd} 21-3$.

z "B. hybridum" indicates all B. hybridum accessions. 
the species B. distachyon and B. hybridum (Table 3). Four-week old plants were used for infection assays and plants were maintained as previously described. Infection assays were performed in a growth room held at $24 \pm 2{ }^{\circ} \mathrm{C}$ with a $14 \mathrm{~h}$ day-length. The experiment was designed as a factorial within an RCBD of four treatments (three $S$. homoeocarpa isolates and PDA control) by 13 Brachypodium accessions, with three replications. Treatments and accessions were randomly assigned within each block and the entire experiment was repeated three times. Blocks were treated as nested within experimental repetitions for statistical analysis. Inoculations were carried out as previously described for $S$. homoeocarpa. At 5 days postinoculation, disease severity on individual plants was rated with the Horsfall-Barratt scale and plants were photographed to allow for comparison of infection type and symptom severity.

Statistical analysis. All data were analyzed using SAS software v.9.3 (SAS Institute, Cary, NC). Horsfall-Barratt ratings were converted to the geometric mean of the percentage range associated with each rating index, which resulted in normal distribution of the data as judged by residual plots and tests for normality within PROC UNIVARIATE. Bd21-3 infection assays

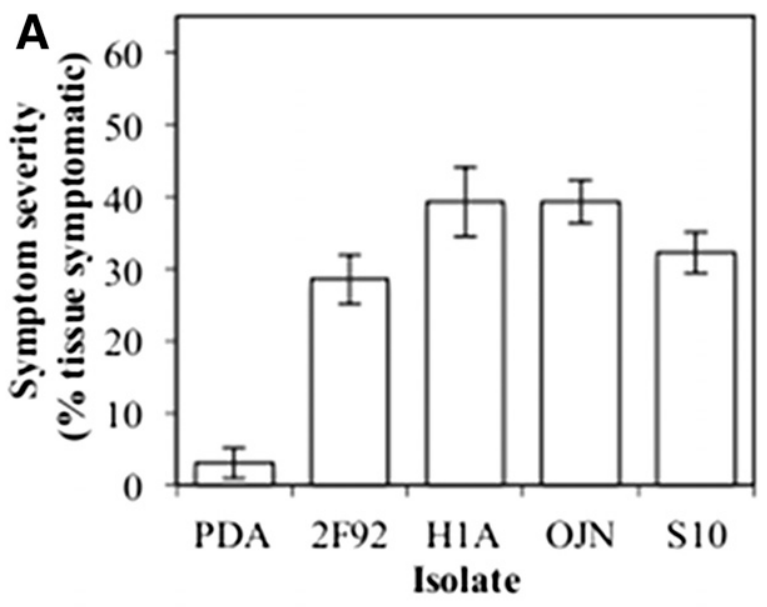

B

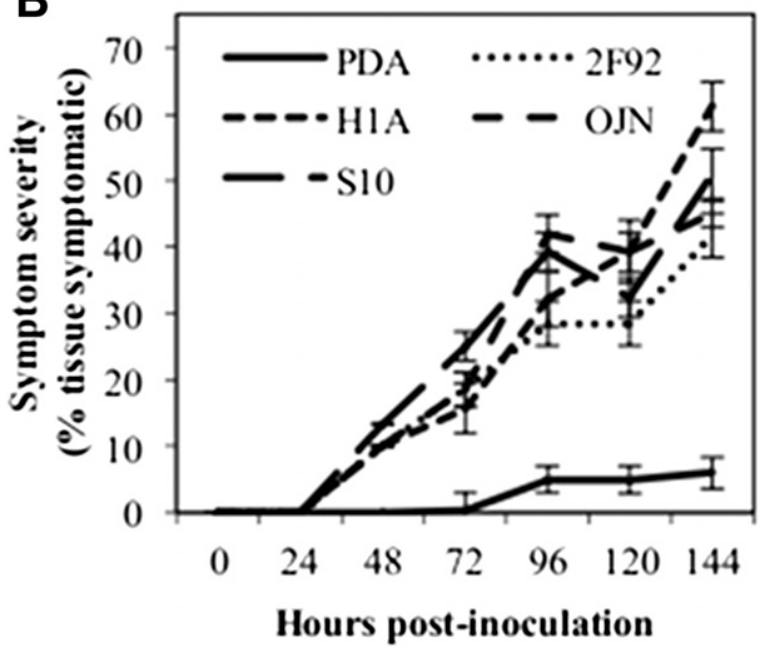

Fig. 1. Disease severity of Sclerotinia homoeocarpa isolates on $\mathrm{Bd} 21-3$ at 5 days postinoculation (dpi). A, Average disease severity rating of whole Brachypodium distachyon plants $5 \mathrm{dpi}$ with one of four $S$. homoeocarpa isolates or a potato dextrose agar (PDA) plug. Disease severity ratings represent the mean severity from three experimental repetitions with three plants per experiment $(n=9)$. Error bars represent \pm one standard error of the mean. B, Progression of infection on Bd21-3 by four isolates of $S$. homoeocarpa and the mockinoculated PDA control. Symptom severity was scored visually every $24 \mathrm{~h}$ for six days. Each data point represents the mean severity from three experimental repetitions with three plants per experiment $(n=9)$. Error bars represent \pm one standard error of the mean. with $S$. homoeocarpa, $R$. solani, and $M$. nivale were analyzed using the PROC MIXED procedure. For analysis of Bd21-3 data, treatment was considered a fixed main effect and experimental replicate was considered a random blocking factor. Analysis of variance (ANOVA) was used to compare treatment means and single degree-of-freedom contrast statements were used to make preplanned comparisons between isolates and inoculated versus mock-inoculated controls. Studentized residual plots and modelfitting criteria (Akaike Information Criterion) were generated and assessed to confirm appropriateness of the models used. When not significant, random factors and interactions were removed from the model used for final analysis if the model-fitting criteria indicated a better fit in the absence of these terms.

$S$. homoeocarpa isolate $\times B$. distachyon accession data were analyzed with the PROC GLIMMIX procedure to allow for the use of slicing to compare levels of one main factor within the different levels of the other. Isolate and accession were both treated as fixed main effects. Initially, block and block(repetition) were treated as random effects. Block(repetition) did not contribute significantly to experimental variability and was excluded from the final analysis. ANOVA was used to compare means for main effects and single degree-of-freedom orthogonal contrast statements were used to make preplanned means comparisons between specific treatments. The SLICE option was used to allow for orthogonal contrast statements comparing levels of one factor within those of the other.

\section{RESULTS}

S. homoeocarpa symptoms, disease severity, and timecourse of infection on Bd21-3. All $S$. homeoocarpa isolates tested were pathogenic on Bd21-3 (Fig. 1). A small amount of bleaching occurred around the site of inoculation in the control pots that received mock inoculation with PDA. This resulted in the approximately $5 \%$ disease severity observed for control plants and was likely due to moderate phytotoxicity of PDA or facilitation of growth by saprophytic fungi naturally present on the grass. Symptoms were similar to those observed on creeping bentgrass in the lab and other turfgrass species under field conditions, including tan lesions with reddish-brown borders (Fig. 2A) (Walsh et al. 1999). Occasionally, hourglass-shaped lesions, a hallmark symptom of $S$. homoeocarpa infection, were observed on stems, sheaths, and leaves (Fig. 2B). In addition to characteristic lesions, necrotic flecking, possibly indicative of a hypersensitive response, was frequently observed in the early stages of infection (24 to $48 \mathrm{~h}$ postinoculation [hpi]) (Fig. 2C). Chlorosis, often leading to necrosis, occasionally presented along leaf margins (Fig. 2D). At 5 days following infection, individual leaf blades appeared wilted and necrotic (Fig. 2E). In severe infections, the entire plant became necrotic and wilted (Fig. 2F).

Brachypodium ecotype-S. homoeocarpa isolate interactions. To determine the presence of natural resistance to $S$. homoeocarpa in Brachypodium spp., thirteen Brachypodium ecotypes were inoculated with three isolates of $S$. homoeocarpa collected from both $\mathrm{C} 3$ and $\mathrm{C} 4$ turfgrass hosts and symptom severity was compared (Table 4). Two of the isolates employed in these experiments were selected from the four Wisconsin isolates initially used to determine pathogenicity on Bd21-3. An additional isolate, LFD8, collected from bermudagrass in North Carolina, was included to increase the host and geographic diversity of $S$. homoeocarpa isolates tested. Due to the separation of polyploid $(2 \mathrm{n}=30) B$. distachyon accessions into the new species $B$. hybridum, this study included three $B$. distachyon ecotypes, nine $B$. hybridum ecotypes, and one inbred B. distachyon line ( $\mathrm{Bd} 21-3)$.

Both accession and isolate had strong effects on symptom severity ( $P=0.0002$ for both) but an accession-isolate interaction was not detected $(P=0.4965)$, indicating that different $S$. homoeocarpa isolates produced similar symptom severity across the Brachypodium ecotypes assessed in this study. Orthogonal contrasts revealed that 
disease severity was greater in $B$. hybridum ecotypes than $B$. distachyon ecotypes $(P<0.0001)$ (Table 3$)$. Bd21-3 is an inbred line developed from the $B$. distachyon wild-type accession PI 254867; consequently, the response of these accessions to $S$. homoeocarpa was of interest but no difference was found between these two lines $(P=$ $0.3553)$. To test for differences in resistance among individual $B$. distachyon accessions to $S$. homoeocarpa, single degree-offreedom orthogonal contrasts were used to compare the two B. distachyon ecotypes PI 245730 and PI 639818 to the inbred line Bd21-3 (Table 3). Disease severity was similar between PI 639818 and $\mathrm{Bd} 21-3$ but a moderate difference in severity was detected between PI 245730 and Bd21-3 $(P=0.02)$. Additional orthogonal contrasts between individual $B$. distachyon ecotypes were performed but no further differences in susceptibility to $S$. homoeocarpa were detected (Table 3).

The majority of Brachypodium ecotypes do not differ in their relative resistance to $S$. homoeocarpa (Table 4). PI 245730 and PI 639818 were more resistant to $S$. homoeocarpa isolates than PI 227011. PI245730 was also more resistant than PI239713; otherwise, resistance to $S$. homoeocarpa did not differ between ecotypes. Because isolate was significant in the overall analysis, means separations were also performed within individual isolates (Table 4). Similar to the overall test, PI227011 and PI239713 had the highest disease severity for both C3 $\mathrm{S}$. homoeocarpa isolates in this study (Table 4). PI245730 had significantly lower symptom severity than the two least resistant ecotypes for both C3 S. homoeocarpa isolates. PI227011 and PI239713 were not significantly different from PI245730 in symptom severity when inoculated with the C4 S. homoeocarpa isolate (Table 4). PI245730 again had the lowest symptom severity,

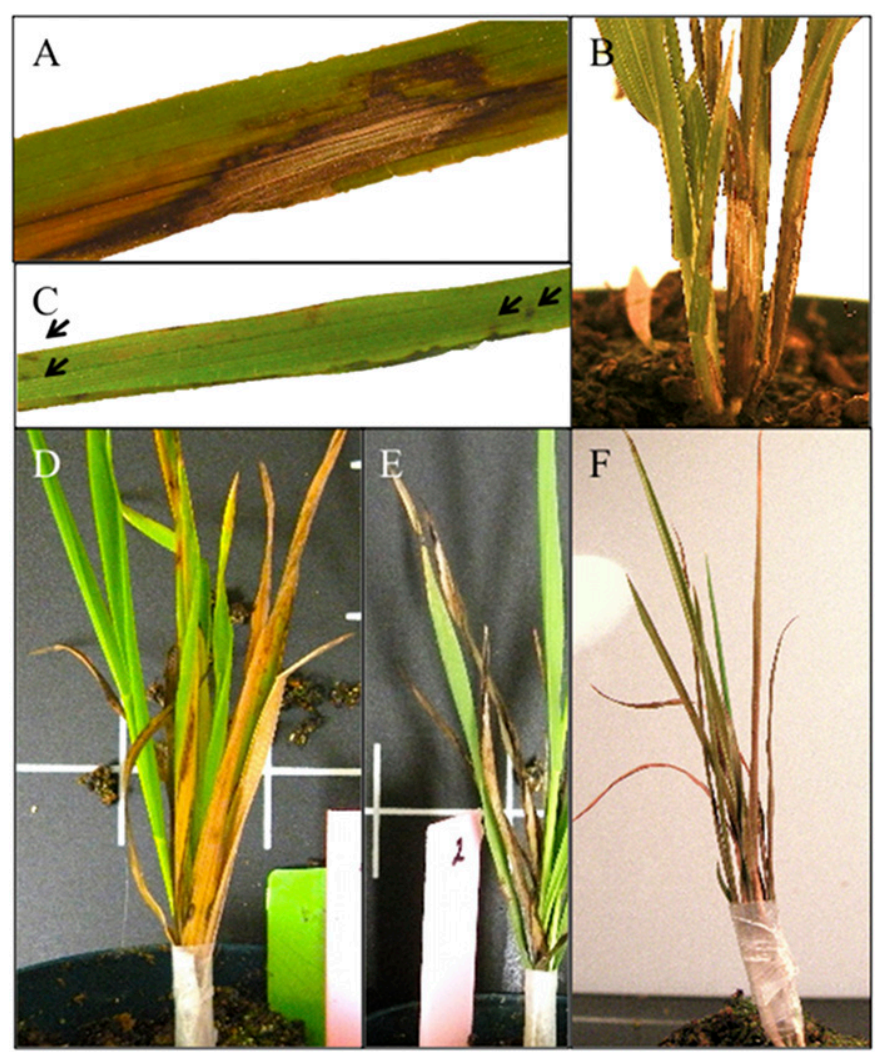

Fig. 2. Symptoms of Sclerotinia homoeocarpa on Bd21-3. A, Characteristic individual lesion, with white center and reddish brown border, frequently observed on infected foliage. B, Hallmark hourglass-shaped lesion on Bd21-3 stem and sheath. C, Necrotic flecking frequently observed early in infection and possibly indicative of a hypersensitive-type response to infection. D, Mild infection resulting in chlorosis of affected foliage and mild necrosis. E, Moderate infection of $\mathrm{Bd} 21-3$ by $S$. homoeocarpa at 5 days postinoculation resulting in necrosis and wilting of some leaf blades while others remain relatively unaffected $\mathbf{F}$, Widespread necrosis and wilting of leaf blades with spread of symptoms to sheaths and stems. along with PI 226629. Only PI 287783 had greater symptom severity than these two ecotypes (Table 4).

$R$. solani symptom development and severity on Bd21-3. Both $R$. solani isolates used in this experiment were pathogenic on $\mathrm{Bd} 21-3$ and there was no difference in aggressiveness between the two isolates (Fig. 3A). Symptoms produced on Bd21-3 were similar to those produced on creeping bentgrass under artificial conditions (Chai et al. 2002) and to those reported in the field on many turfgrass species (Smiley et al. 2005). Plant symptoms included tan to gray lesions along leaf blades with dark-brown borders. Chlorosis spreading along leaf blades frequently accompanied these lesions (Fig. 3B and C). Lesion phenotype varied from small and circular to long and irregularly shaped (Fig. 3B and C). Tips of severely infected leaf blades occasionally became necrotic and tissue surrounding the site of inoculation was frequently damaged (Fig. 3C). Symptoms were primarily observed on leaf blades and rarely advanced to stems and sheaths. Sparse white mycelia were occasionally produced in infected areas of host tissue.

M. nivale symptom development and severity on Bd21-3. $M$. nivale isolates used in this study were pathogenic on $\mathrm{Bd} 21-3$ but differed significantly in aggressiveness (Fig. 4A). Symptoms produced by $\mathrm{BH} 7$ generally included necrosis of leaf blades that occasionally spread to ligules, sheaths, and culms. Chlorosis was observed spreading along infected leaf blades (Fig. 4B). Sparse white mycelia were frequently observed on infected plants (Fig. 4B). The more aggressive isolate, MN5, produced large, dark-brown necrotic lesions affecting blades, ligules, sheaths, and culms (Fig. 4C). Chlorosis was frequently noted in leaf blades and spread beyond areas of necrosis (Fig.4D). Severely affected leaf blades were completely necrotic and occasionally appeared wilted (Fig. 4C). As with isolate $\mathrm{BH} 7$, sparse white mycelia were formed in areas of necrotic tissue (Fig. 4C).

\section{DISCUSSION}

The aim of the present study was to determine the potential for use of $B$. distachyon as a model host for three major fungal pathogens of amenity turfgrasses. Additionally, this research investigated pathogenesis and ecotype-isolate interactions of various Brachypodium accessions with the dollar spot pathogen $S$. homoeocarpa. The results of these studies clearly demonstrate compatible interactions between $\mathrm{Bd} 21-3$ and $S$. homoeocarpa, M. nivale, and $R$. solani. Additionally, screening of diverse Brachypodium ecotypes with C3 and $\mathrm{C} 4$ isolates of $S$. homoeocarpa indicated that genetic variability exists within Brachypodium accessions that can be leveraged for studies of host-pathogen interactions for S. homoeocarpa and other prominent fungal pathogens of turfgrass.

TABLE 4. Means separation for symptom severity of Brachypodium accessions inoculated with Sclerotinia homoeocarpa

\begin{tabular}{lllll}
\hline & \multicolumn{4}{c}{ Means separation $^{\mathrm{z}}$} \\
\cline { 2 - 5 } Accession & All isolates & \multicolumn{1}{c}{ 2F92-1 } & \multicolumn{1}{c}{ OJN9 } & LFD8 \\
\hline PI 227011 & $62.4 \mathrm{~A}$ & $70.0 \mathrm{~A}$ & $68.9 \mathrm{~A}$ & $48.3 \mathrm{AB}$ \\
PI 239713 & $58.1 \mathrm{AB}$ & $59.4 \mathrm{AB}$ & $65.0 \mathrm{~A}$ & $50.0 \mathrm{AB}$ \\
PI 287783 & $51.2 \mathrm{ABC}$ & $47.8 \mathrm{BDC}$ & $52.8 \mathrm{ABC}$ & $52.9 \mathrm{~A}$ \\
PI 533015 & $51.0 \mathrm{ABC}$ & $45.0 \mathrm{BDC}$ & $58.1 \mathrm{ABC}$ & $50.0 \mathrm{AB}$ \\
PI 254868 & $48.0 \mathrm{ABC}$ & $53.9 \mathrm{ABC}$ & $50.7 \mathrm{ABC}$ & $39.4 \mathrm{AB}$ \\
Bd21-3 & $48.3 \mathrm{ABC}$ & $40.6 \mathrm{BDC}$ & $58.1 \mathrm{ABC}$ & $46.3 \mathrm{AB}$ \\
PI 372187 & $49.2 \mathrm{ABC}$ & $45.6 \mathrm{BDC}$ & $63.1 \mathrm{AB}$ & $38.2 \mathrm{AB}$ \\
PI 226629 & $46.9 \mathrm{ABC}$ & $47.5 \mathrm{BDC}$ & $60.0 \mathrm{AB}$ & $33.1 \mathrm{~B}$ \\
PI 239714 & $45.8 \mathrm{ABC}$ & $40.0 \mathrm{BDC}$ & $54.4 \mathrm{ABC}$ & $43.1 \mathrm{AB}$ \\
PI 233228 & $44.3 \mathrm{BC}$ & $43.9 \mathrm{BDC}$ & $42.2 \mathrm{BC}$ & $46.7 \mathrm{AB}$ \\
PI 254867 & $43.7 \mathrm{BC}$ & $43.3 \mathrm{BDC}$ & $39.4 \mathrm{C}$ & $48.3 \mathrm{AB}$ \\
PI 639818 & $42.8 \mathrm{BC}$ & $38.9 \mathrm{DC}$ & $52.2 \mathrm{ABC}$ & $37.2 \mathrm{AB}$ \\
PI 245730 & $35.4 \mathrm{C}$ & $28.9 \mathrm{D}$ & $42.8 \mathrm{BC}$ & $34.4 \mathrm{~B}$ \\
\hline
\end{tabular}

z Accessions with the same letter are not significantly different from each other by Fisher's protected least significant difference test, $\alpha=0.05$. 
Aside from dollar spot, brown patch is one of the most frequently encountered diseases on amenity turfgrass (Bokmeyer et al. 2009), and pink snow mold is the primary cool-season disease of turfgrasses throughout the globe (Smiley et al. 2005). In the present research, isolates of both $R$. solani and $M$. nivale caused symptoms on $B$. distachyon inbred line $\mathrm{Bd} 21-3$ under temperature and humidity conditions that are ideal for infection of turfgrass hosts by these pathogens. This suggests that both pathogens have requirements for infection on B. distachyon similar to those for natural turfgrass hosts. $R$. solani lesions on $B$. distachyon closely matched those observed previously on creeping bentgrass and other turfgrass species, including the formation of irregularly shaped tan lesions with darkred to brown borders between diseased and healthy tissue (Smiley et al. 2005). Due to the lack of empirical data on development of brown patch symptoms on turfgrass in controlled settings, it is difficult to make additional direct comparisons; however, further studies of $R$. solani pathogenesis using $B$. distachyon as a model will contribute to better understanding of the physiological and molecular mechanisms of turf-type grass infection by this pathogen. $R$. solani AG2-2 IIIB, the primary turfgrass-infecting anastomosis group (AG), affects other hosts in the Poaceae family (Ogoshi 1987). Information gained from the $B$. distachyon pathosystem can be extended to enhance understanding of $R$. solani pathogenesis in these hosts as well. The wheat root rot pathogen $R$. solani AG8 is also compatible with $B$. distachyon, and natural ecotypes vary in resistance to an isolate in this AG (Schneebeli et al. 2016). These results are consistent with the present research and indicate that $B$. distachyon may provide a general model pathosystem for $R$. solani AG that infect cool-season grasses.

In addition to being a major turfgrass pathogen, $M$. nivale is the causal agent of pink snow mold, also known as Microdochium patch, on winter wheat, rye, barley, and oat (Pettitt et al. 1993; Simpson et al. 2000). Some research on M. nivale-host interactions has been performed in the wheat pathosystem but the relatedness of $M$. nivale isolates from turf and cereal crop plants is not well understood (Jewell and Hsiang 2013; Lees et al 1995; Litschko and

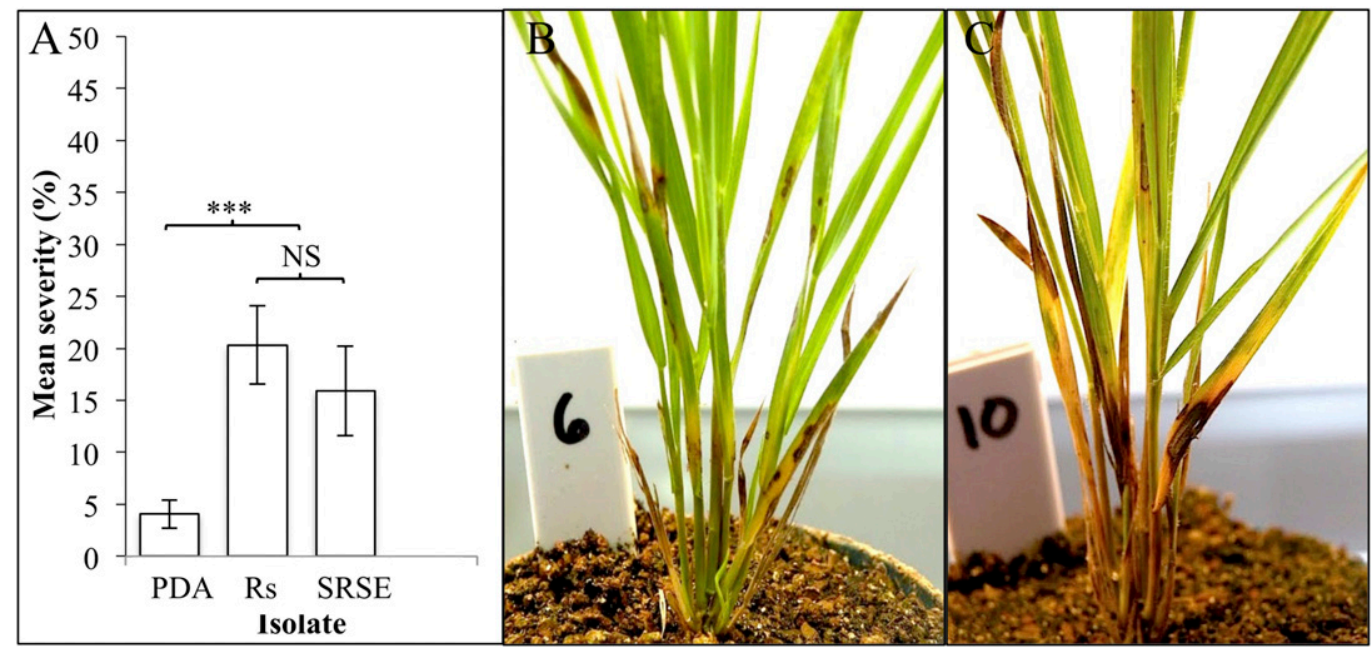

Fig. 3. Infection of Brachypodium distachyon inbred line Bd21-3 with Rhizoctonia solani. A, Mean symptom severity of Bd21-3 5 days following inoculation with $R$. solani isolate Rs or SRSe or with a potato dextrose agar (PDA) plug. Single degree-of-freedom orthogonal contrast statements were used to compare between $R$. solani isolates and between $R$. solani isolates and the PDA control at $\alpha=0.05$. NS $=$ no significant difference detected and $* * *=P<0.0001$. B, Mild symptoms of $R$. solani infection on Bd21-3, including chlorosis and small, necrotic lesions. C, Moderate infection of Bd21-3 by $R$. solani with necrotic leaf tips, severe necrosis surrounding the site of inoculation, and the presence of sparse mycelia near the site inoculation. Error bars represent \pm one standard error of the mean.

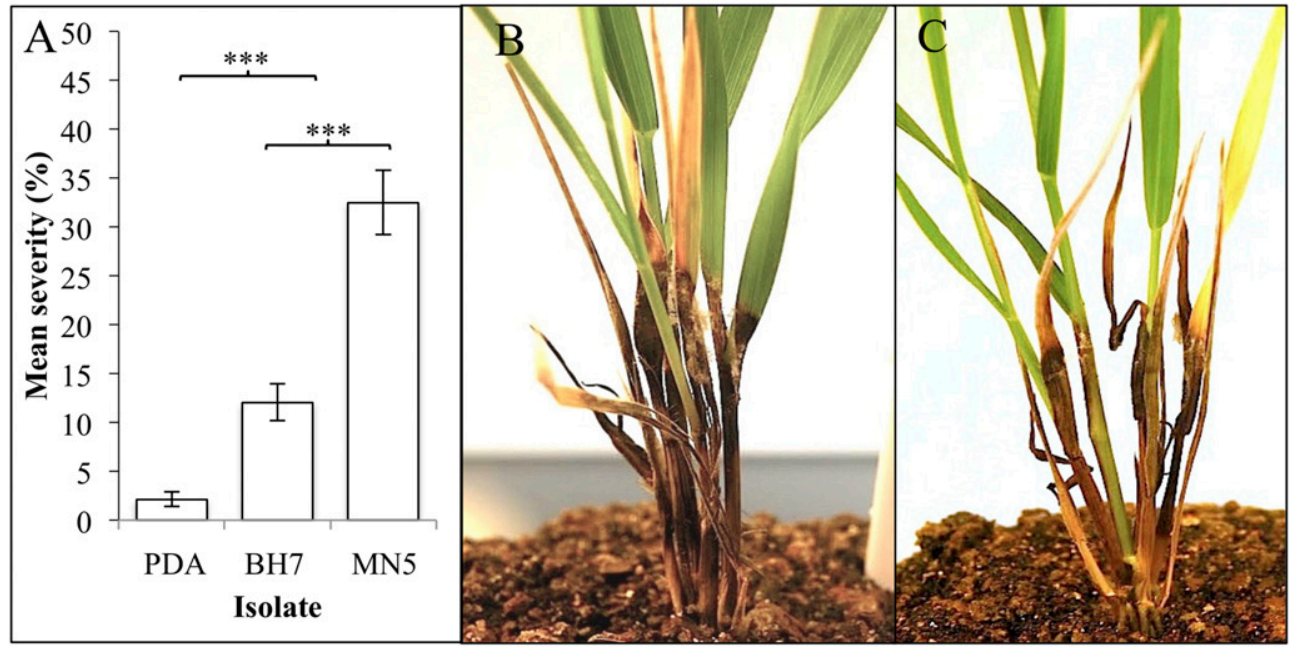

Fig. 4. Infection of Brachypodium distachyon inbred line Bd21-3 with Microdochium nivale. A, Mean symptom severity of Bd21-3 5 days following inoculation with $M$. nivale isolate BH7 or MN5 or with a potato dextrose agar (PDA) plug. Single degree-of-freedom orthogonal contrast statements were used to compare between $M$. nivale isolates and between $M$. nivale isolates and the PDA control at $\alpha=0.05 ; * * *=P<0.0001$. B, Symptoms of less aggressive $M$. nivale isolate $\mathrm{BH} 7$ on Bd21-3. C, Moderate infection of Bd21-3 by M. nivale isolate MN5, including necrosis, wilting, and production of sparse mycelia at the site of infection. Error bars represent \pm one standard error of the mean. 
Burpee 1987; Simpson et al. 2000). Consequently, a model system for studying $M$. nivale-host interactions will be helpful for turfgrass pathology and may extend to additional economically important crops such as wheat, barley, and ryegrass. On individual turfgrass blades, symptoms of $M$. nivale infection are nondistinct, with generalized water soaking and necrosis, as well as the presence of tufts of aerial white mycelia (Smiley et al. 2005). The symptoms observed on $B$. distachyon plants artificially inoculated with agar plugs of M. nivale were remarkably similar (Fig. 4B and C). Dark, water-soaked lesions formed around the site of inoculation both upward into leaf blades and downward into culms. Similar to turfgrass infections, fluffy white mycelia were observed protruding from the border between healthy and diseased tissue. The name "pink snow mold" derives from the presence of pinkish mycelia and sporodochia that appear on infected turf, giving symptomatic areas a pinkish coloration. M. nivale sporulation is sunlight dependent; thus, this phenomenon was not observed on $B$. distachyon in the present study but may be possible with the right environmental conditions (Smiley et al. 2005). M. nivale reisolated from symptomatic $B$. distachyon plants produced abundant conidia in culture, indicating no negative effects on the fungus from exposure to $B$. distachyon.

Due to growing concerns over extensive fungicide use for dollar spot control and increasing issues with resistance to common fungicide groups in S. homoeocarpa populations (Burpee 1997; Miller et al. 2002; Orshinsky et al. 2012a, b; Putman et al. 2010), there has been a resurgence in research on $S$. homoeocarpa pathogenesis. Orshinsky and colleagues (2012a) used histological methods and microscopy to study the infection process of virulent, hypovirulent, and asymptomatic isolates of $S$. homoeocarpa on detached creeping bentgrass leaves. In these studies, plugs from 5-day-old PDA cultures of $S$. homoeocarpa were placed on leaf blades over moistened filter paper in Parafilm-sealed Petri plates. In agreement with our studies on intact plants, appressoria, particularly in association with stomata, and intercellular hyphal growth were observed by 48 hpi (Orshinsky et al. 2012a). In the current research, symptoms of $S$. homoeocarpa infection began appearing by $48 \mathrm{hpi}$ and developed rapidly over the following days.

No Brachypodium accession-S. homoeocarpa isolate interaction was noted in this research, indicating that $S$. homoeocarpa employs a generalist pathogenesis strategy and that resistance-avirulence gene interactions do not occur between $S$. homoeocarpa and B. distachyon. This corresponds with interactions reported for turfgrass hosts and is part of the reason that breeding for dollar spot resistant turfgrass cultivars presents a significant challenge to turfgrass breeders (Bonos et al. 2003). It is likely that both natural hosts and Brachypodium spp. rely on quantitative resistance mechanisms to combat $S$. homoeocarpa infection. Identification of these mechanisms in Brachypodium spp. could be used to identify similar traits in turfgrasses.

Previous studies have demonstrated the utility of $B$. distachyon as a model host for various cereal rust pathogens that affect turfgrass species (Ayliffe et al. 2013; Barbieri et al. 2011; Beirn et al. 2011; Figueroa et al. 2013). The present research extends the applications of $B$. distachyon as a tool for studying host-pathogen interactions in turfgrasses to three additional major fungal diseases of these hosts: dollar spot, brown patch, and pink snow mold. No genomic sequence data is publicly available for popular turfgrass species, and large-scale transcriptomic analyses of endophyte or pathogeninfected turfgrass hosts are limited (Ambrose and Belanger 2012; Orshinsky et al. 2012b). Additionally, the only genetic tools currently available for genetic manipulation of turfgrass species is Agrobacterium-mediated transformation, which is time consuming and complicated by the complex genomes of most turfgrass species (Bajaj et al. 2006; Dong and Qu 2005; Ge et al. 2006; Luo et al. 2004). In contrast, the multitude of public genetic resources and molecular tools available for B. distachyon, as well as the ease with which this species can be cultivated, inbred, and inoculated, make it an ideal model for studying the molecular aspects of host resistance to major turfgrass pathogens. In this research, Brachypodium accessions with significant differences in resistance to $S$. homoeocarpa were identified. Inbred lines derived from these accessions and selected for resistance or susceptibility to S. homoeocarpa will provide useful tools for identification of genes involved in host resistance to this pathogen. In the future, similar studies that evaluate the resistance of Brachypodium accessions to $R$. solani and $M$. nivale will be needed to identify the best accessions to use for dissection of host resistance mechanisms to these pathogens.

This research demonstrated that B. distachyon inbred line $\mathrm{Bd} 21-3$ is a compatible host to the causal agents of turfgrass dollar spot, brown patch, and pink snow mold diseases. These are three of the most economically important diseases of turfgrass and account for the vast majority of fungicide sprays in high-value turf settings. Symptoms of these diseases produced on $\mathrm{Bd} 21-3$ mimic those observed on natural turfgrass hosts and indicate that $B$. distachyon is a useful model pathosystem to study molecular host-pathogen interactions of these diseases. The use of $B$. distachyon as a model will accelerate the pace at which key genes underlying host resistance or susceptibility to these causal agents of these diseases are identified and will enhance breeding efforts for diseaseresistant turfgrass cultivars. Targeted breeding efforts will decrease the time needed to produce turfgrass cultivars resistant to dollar spot, brown patch, and pink snow mold and will significantly decrease dependence upon chemical control, resulting in more sustainable and environmentally friendly turfgrass disease management.

\section{ACKNOWLEDGMENTS}

We thank W. Kreuser for providing seed of Bd21-3, D. Garvin for providing seed of additional $B$. distachyon inbred lines and advice on B. distachyon cultivation, and S. Soper for assistance in Brachypodium inoculations and experimental set-up.

\section{LITERATURE CITED}

Ambrose, K. V., and Belanger, F. C. 2012. SOLiD-SAGE of endophyte-infected red fescue reveals numerous effects on host transcriptome and an abundance of highly expressed fungal secreted proteins. PLoS One 7:e53214.

Ayliffe, M., Singh, D., Park, R., Moscou, M., and Pryor, T. 2013. Infection of Brachypodium distachyon with selected grass rust pathogens. Mol. PlantMicrobe Interact. 26:946-957.

Baird, J. H., Basta, N. T., Huhnke, R. L., Johnson, G. V., Payton, M. E., Storm, D. E., Wilson, C. A., Smolen, M. D., Martin, D. L., and Cole, J. T. 1999. Best management practices to reduce pesticide and nutrient runoff from turf. Pages 268-293 in: Fate and Management of Turfgrass Chemicals. J. M. Clark and M. P. Kenna, eds. American Chemical Society, Washington, DC.

Bajaj, S., Ran, Y., Phillips, J., Kularajathevan, G., Pal, S., Cohen, D., Elborough, K., and Puthigae, S. 2006. A high throughput Agrobacterium tumefaciens-mediated transformation method for functional genomics of perennial ryegrass (Lolium perenne L.). Plant Cell Rep. 25:651-659.

Barbieri, M., Agrarie, S., Emilia, R., and Amendola, V. 2011. Host status of false brome grass to the leaf rust fungus Puccinia brachypodii and the stripe rust fungus $P$. striiformis. Plant Dis. 95:1339-1345.

Baris, R. D., Cohen, S. Z., Barnes, N. L., Lam, J., and Ma, Q. 2010. Quantitative analysis of over 20 years of golf course monitoring studies. Environ. Toxicol. Chem. 29:1224-1236.

Beard, J. B. 1973. Turfgrass: Science and Culture. Prentice-Hall, Englewood Cliffs, NJ.

Beirn, L. A., Moy, M., Meyer, W. A., Clarke, B. B., and Crouch, J. A. 2011. Molecular analysis of turfgrass rusts reveals the widespread distribution of Puccinia coronata as a pathogen of Kentucky bluegrass in the United States. Plant Dis. 95:1547-1557.

Belanger, F. C., Bonos, S., and Meyer, W. A. 2004. Dollar spot resistant hybrids between creeping bentgrass and colonial bentgrass. Crop Sci. 44:581-586.

Bokmeyer, J. M., Bonos, S. A., and Meyer, W. A. 2009. Inheritance characteristics of brown patch resistance in all fescue. Crop Sci. 49:2302-2308.

Bonos, S. A., Casler, M. D., and Meyer, W. A. 2003. Inheritance of dollar spot resistance in Creeping Bentgrass. Crop Sci. 43:2189-2196.

Bonos, S. A., Casler, M. D., and Meyer, W. A. 2004. Plant responses and characteristics associated with dollar spot resistance in creeping bentgrass. Crop Sci. 44:1763-1769. 
Bonos, S. A., Clarke, B. B., and Meyer, W. A. 2006. Breeding for disease resistance in the major cool-season turfgrasses. Annu. Rev. Phytopathol. 44:213-234.

Bossolini, E., Wicker, T., Knobel, P. A., and Keller, B. 2007. Comparison of orthologous loci from small grass genomes Brachypodium and rice: Implications for wheat genomics and grass genome annotation. Plant J. 49:704-717.

Bragg, J. N., Wu, J., Gordon, S. P., Guttman, M. E., Thilmony, R., Lazo, G. R., Gu, Y. Q., and Vogel, J. P. 2012. Generation and characterization of the Western Regional Research Center T-DNA insertional mutant collection. PLoS One 7e:41916.

Breuninger, J. M., Welterlen, M. S., Augustin, B. J., Cline, V., and Morris, K. 2013. Pages 37-104 in: Turfgrass: Biology, Use, and Management. J. C. Stier, B. P. Horgan, and S. A. Bonos, eds. American Society of Agronomy, Crop Science Society of America, Soil Science Society of America, Madison, WI.

Burpee, L. L. 1997. Control of dollar spot of creeping bentgrass caused by an isolate of Sclerotinia homoeocarpa resistant to benzimidazole and demethylation-inhibitor fungicides. Plant Dis. 81:1259-1263.

Catalán, P., Müller, J., Hasterok, R., Jenkins, G., Mur, L. A. J., Langdon, T., Betekhtin, A., Siwinska, D., Pimentel, M., and López-Alvarez, D. 2012. Evolution and taxonomic split of the model grass Brachypodium distachyon. Ann. Bot. 109:385-405.

Chai, B., Maqbool, S. B., Hajela, R. K., Green, D., Vargas, J. M., Warkentin, D., Sabzikar, R., and Sticklen, M. B. 2002. Cloning of a chitinase-like cDNA ( $h s 2)$, its transfer to creeping bengtgrass (Agrostis palustris Huds.) and development of brown patch (Rhizoctonia solani) disease resistant transgenic lines. Plant Sci. 163:183-193.

Chutimanitsakun, Y., Nipper, R.W., Cuesta-Marcos, A., Cistue, L., Corey, A., Filichkina, T., Johnson, E.A., and Hayes, P.M. 2011. Construction and application of QTL analysis of a Restriction Site Associated DNA (RAD) linkage map in barley. BMC Genomics 12:4. DOI: 10:11861/1471-2164-12-4.

Dong, S., and Qu, R. 2005. High efficiency transformation of tall fescue with Agrobacterium tumefaciens. Plant Sci. 168:1453-1458.

Draper, J., Mur, L. A., Jenkins, G., Ghosh-Biswas, G. C., Bablak, P., Hasterok, R., and Routledge, A. P. 2001. Brachypodium distachyon. A new model system for functional genomics in grasses. Plant Physiol. 127:1539-1555.

Figueroa, M., Alderman, S., Garvin, D. F., and Pfender, W. F. 2013. Infection of Brachypodium distachyon by formae speciales of Puccinia graminis: Early infection events and host-pathogen incompatibility. PLoS One 8:e56857.

Fitzgerald, T. L., Powell, J. J., Schneebeli, K., Hsia, M. M., Gardiner, D. M., Bragg, J. N., McIntyre, C. L., Manners, J. M., Ayliffe, M., Watt, M., Vogel, J. P., Henry, R. J., and Kazan, K. 2015. Brachypodium as an emerging model for cereal-pathogen interactions. Ann. Bot. 115:717-731.

Garvin, D. F., Gu, Y.-Q., Hasterok, R., Hazen, S. P., Jenkins, G., Mockler, T. C., Mur, L. J., and Vogel, J. P. 2008. Development of genetic and genomic research resources for, a new model system for grass crop research. Crop Sci. 48:S-69-S-84

Ge, Y., Norton, T., and Wang, Z.-Y. 2006. Transgenic zoysiagrass (Zoysia japonica) plants obtained by Agrobacterium-mediated transformation. Plant Cell Rep. 25:792-798.

Gomez, L. D., Bristow, J. K., Statham, E. R., and McQueen-Mason, S. J. 2008. Analysis of saccharification in Brachypodium distachyon stems under mild conditions of hydrolysis. Biotechnol. Biofuels 1:15.

Horsfall, J. G., and Barratt, R. W. 1945. An improved grading system for measuring plant diseases. (Abstr.) Phytopathology 35:655.

Jewell, L. E., and Hsiang, T. 2013. Multigene differences between Microdochium nivale and Microdochium majus. Botany 91:99-106.

Jia, Y., Liu, G., Park, D.-S., and Yang, Y. 2012. Inoculation and scoring methods for rice sheath blight disease. Methods Mol. Biol. 956:257-268.

Kellogg, E. A. 2001. Evolutionary history of the grasses. Plant Physiol. 125: 1198-1205.

Kerns, J. P., and Tredway, L. P. 2013. Advances in turfgrass pathology since 1990. Pages 733-777 in: Turfgrass: Biology, Use, and Management. J. C. Stier, B. P. Horgan, and S. A. Bonos, eds. American Society of Agronomy, Crop Science Society of America, Soil Science Society of America, Madison, WI.

Koch, P., Grau, C. R., Jo, Y., and Jung, G. 2009. Thiophanate-methyl and propiconazole sensitivity in Sclerotinia homoeocarpa populations from golf courses in Wisconsin and Massachusetts. Plant Dis. 93:100-105.

Koppenhöfer, A. M., Latin, R., McGraw, B. A., Brosnan, J. T., and Crow, W. T. 2013. Integrated pest management. Pages 933-1007 in: Turfgrass: Biology, Use, and Management. J. C. Stier, B. P. Horgan, and S. A. Bonos, eds. American Society of Agronomy, Crop Science Society of America, Soil Science Society of America, Madison, WI.

Latin, R. 2011. A Practical Guide to Turfgrass Fungicides. The American Phytopathological Society, St. Paul, MN.

Lees, A. K., Nicholson, P., Rezanoor, H. N., and Parry, D. W. 1995. Analysis of variation within Microdochium nivale from wheat: Evidence for a distinct sub-group. Mycol. Res. 99:103-109.

Leinauer, B., and Devitt, D. A. 2013. Irrigation science and technology. Pages 1075-1133 in: Turfgrass: Biology, Use, and Management. J. C. Stier, B. P.
Horgan, and S. A. Bonos, eds. American Society of Agronomy, Crop Science Society of America, Soil Science Society of America, Madison, WI.

Litschko, L., and Burpee, L. L. 1987. Variation among isolates of Microdochium nivale collected from wheat and turfgrasses. Trans. Br. Mycol. Soc. 89:252-256.

Luo, H., Hu, Q., Nelson, K., Longo, C., Kausch, A. P., Chandlee, J. M., Wipff, J. K., and Fricker, C. R. 2004. Agrobacterium tumefaciens-mediated creeping bentgrass (Agrostis stolonifera L.) transformation using phosphinothricin selection results in a high frequency of single-copy transgene integration. Plant Cell Rep. 22:645-652.

Lyons, C. W. P., and Scholthof, K. G. 2015. Watching grass grow: The emergence of Brachypodium distachyon as a model for the Poaceae. Pages 479-501 in: New Perspectives on the History of Life Sciences and Agriculture. D. Phillips and S. Kingsland, eds. Springer International Publishing, Cham, Switzerland.

Miller, G. L., Stevenson, K. L., and Burpee, L. L. 2002. Sensitivity of Sclerotinia homoeocarpa isolates to propiconazole and impact on control of dollar spot. Plant Dis. 86:1240-1246.

Ogoshi, A. 1987. Ecology and pathogenicity of anastomosis and intraspecific groups of Rhizoctonia solani Kuhn. Annu. Rev. Phytopathol. 25:125-143.

Orshinsky, A. M., Boehm, M. J., and Boland, G. J. 2012a. Plant wounding and Ophiostoma mitovirus $3 a$ (OMV3a) influence infection of creeping bentgrass by Sclerotinia homoeocarpa. Can. J. Plant Pathol. 34:493-506.

Orshinsky, A. M., Hu, J., Opiyo, S. O., Reddyvari-Channarayappa, V., Mitchell, T. K., and Boehm, M. J. 2012b. RNA-seq analysis of the Sclerotinia homoeocarpa-creeping bentgrass pathosystem. PLoS One 7:e41150.

Parker, D., Beckmann, M., Enot, D. P., Overy, D. P., Rios, Z. C., Gilbert, M., Talbot, N., and Draper, J. 2008. Rice blast infection of Brachypodium distachyon as a model system to study dynamic host/pathogen interactions. Nat. Protoc. 3:435-445.

Peraldi, A., Beccari, G., Steed, A., and Nicholson, P. 2011. Brachypodium distachyon: A new pathosystem to study Fusarium head blight and other Fusarium diseases of wheat. BMC Plant Biol. 11:100

Peraldi, A., Griffe, L. L., Burt, C., McGrann, G. R. D., and Nicholson, P. 2014. Brachypodium distachyon exhibits compatible interactions with Oculimacula spp. and Ramularia collo-cygni, providing the first pathosystem model to study eyespot and ramularia leaf spot diseases. Plant Pathol. 63: 554-562.

Pettitt, T. R., Parry, D. W., and Polley, R. W. 1993. Improved estimation of the incidence of Microdochium nivale in winter wheat stems in England and Wales, during 1992, by use of benomyl agar. Mycol. Res. 97: 1172-1174.

Putman, A. I., Jung, G., and Kaminski, J. E. 2010. Geographic distribution of fungicide-insensitive Sclerotinia homoeocarpa isolates from golf courses in the Northeastern United States. Plant Dis. 94:186-195.

Rioux, R. A., Shultz, J., Garcia, M., Willis, D. K., Casler, M., Bonos, S., Smith, D., and Kerns, J. 2014. Sclerotinia homoeocarpa overwinters in turfgrass and is present in commercial seed. PLoS One 9:e110897.

Routledge, A. P. M., Shelley, G., Smith, J. V., Talbot, N. J., Draper, J., and Mur, L. A. J. 2004. Magnaporthe grisea interactions with the model grass Brachypodium distachyon closely resemble those with rice (Oryza sativa). Mol. Plant Pathol. 5:253-265.

Sandoya, G. V., and de Oliviera Buanafina, M. M. 2014. Differential responses of Brachypodium distachyon genotypes to insect and fungal pathogens. Physiol. Mol. Plant Pathol. 85:53-64.

Schneebeli, K., Mathesius, U., Zwart, A. B., Bragg, J. N., Vogel, J. P., and Watt, M. 2016. Brachypodium distahchyon genotypes vary in resistance to Rhizoctonia solani AG8. Funct. Plant Biol. 43:189-198.

Simpson, D. R., Rezanoor, H. N., Parry, D. W., and Nicholson, P. 2000. Evidence for differential host preference in Microdochium nivale var. majus and Microdochium nivale var. nivale. Plant Pathol. 49: 261-268.

Smiley, R. W., Dernoeden, P. H., and Clark, B. B. 2005. Compendium of Turfgrass Diseases, 3rd ed. The American Phytopathological Society, St. Paul, MN.

Spangenberg, G. C., Forster, J. W., Edwards, D., John, U., Mouradov, A., Emmerling, M., Batley, J., Felitti, S., Cogan, N. O. I., Smith, K. F., Dobrowolski, M. P., and Humphreys, M. O. 2005. Future directions in the molecular breeding of forage and turf. Pages 83-97 in: Molecular Breeding for the Genetic Improvement of Forage Crops and Turf. Proc. 4th Int. Symp. Mol. Breed. Forage Turf, A Satellite Workshop XXth Int. Grassl. Congr. Aberystwyth, Wales. Wageningen Academic Publishers, Dordrecht, The Netherlands.

Studer, B., Boller, B., Bauer, E., Posselt, U. K., Widmer, F., and Kölliker, R. 2007. Consistent detection of QTLs for crown rust resistance in Italian ryegrass (Lolium multiflorum Lam.) across environments and phenotyping methods. Theor. Appl. Genet. 115:9-17.

The International Brachypodium Initiative. 2010. Genome sequencing and analysis of the model grass Brachypodium distachyon. Nature 463: 763-768. 
Walsh, B., Ikeda, S. S., and Boland, G. J. 1999. Biology and management of dollar spot (Sclerotinia homoeocarpa); an important disease of turfgrass. HortScience 34:13-21.

White, T. J., Bruns, T., Lee, S. J. W. T., and Taylor, J. W. 1990. Amplification and direct sequencing of fungal ribosomal RNA genes for phylogenetics. Pages 315-322 in: PCR Protocols: A Guide to Methods and Applications. M. A. Innis, D. H. Gelfand, J. J. Sninsky, and T. J. White, eds. Academic Press Inc., New York.

Zhang, W., Olson, E., Saintenac, C., Rouse, M., Abate, Z., Jin, Y., Akhunov, E., Pumphrey, M., and Dubcovsky, J. 2010. Genetic maps of stem rust resistance gene S35 in diploid and hexaploid wheat. Crop Sci. 50: 2464-2474.

Zhao, H., Yu, J., You, F. M., Luo, M., and Peng, J. 2011. Transferability of microsatellite markers from Brachypodium distachyon to Miscanthus sinensis, a potential biomass crop. J. Integr. Plant Biol. 53: 232-245.

Zhong, S., Ali, S., Leng, Y., Wang, R., and Garvin, D. F. 2015. Brachypodium-Cochliobolus sativus pathosystem is a new model for studying plant-fungal interactions in cereal crops. Phytopathology 105: 482-489. 